\title{
Lateral Slope Effect on Tipping Behavior of a Tractor Encountering an Obstacle (Model Development)
}

\section{$\mathrm{Li}$, Zhen}

Laboratory of Bioproduction Engineering, Division of Bioproduction Environmental Sciences, Department of Agro-environmental Sciences, Graduate School of Bioresource and Bioenvironmental Sciences, Kyushu University

\section{Mitsuoka, Muneshi}

Laboratory of Bioproduction Engineering, Division of Bioproduction Environmental Sciences, Department of Agro-environmental Sciences, Faculty of Agriculture, Kyushu University

Inoue, $\mathrm{Eiji}$

Laboratory of Bioproduction Engineering, Division of Bioproduction Environmental Sciences, Department of Agro-environmental Sciences, Faculty of Agriculture, Kyushu University

Okayasu, Takashi

Laboratory of Bioproduction Engineering, Division of Bioproduction Environmental Sciences, Department of Agro-environmental Sciences, Faculty of Agriculture, Kyushu University

他

https://doi.org/10.5109/1467645

出版情報：九州大学大学院農学研究院紀要. 59 (2)，pp. 345-349，2014-08-29. Faculty of Agriculture, Kyushu University

バージョン :

権利関係 : 


\title{
Lateral Slope Effect on Tipping Behavior of a Tractor Encountering an Obstacle (Model Development)
}

\author{
Zhen LI ${ }^{1}$, Muneshi MITSUOKA ${ }^{2 *}$, Eiji INOUE ${ }^{2}$, Takashi OKAYASU ${ }^{2}$ \\ and Yasumaru HIRAI ${ }^{2}$
}

\author{
Laboratory of Bioproduction Engineering, Division of Bioproduction Environmental Sciences, \\ De-partment of Agro-environmental Sciences, Faculty of Agriculture, \\ Kyushu University, Fukuoka 812-8581, Japan \\ (Received April 25, 2014 and accepted May 12, 2014)
}

\begin{abstract}
A three-dimensional mathematical model of tractor on lateral slopes was developed in this study. The model considers the nonlinear geometric relationships of the arms of the ground supporting forces when the tractor passes over a half sine curve obstacle. It is subsequently ap-plicable to large rotations of a tractor. Meanwhile, the change of the direction of a supporting force due to the interaction between tractor pitch and roll motions and its result in corresponding tire deformation are the concern of this study. Given the transformation matrix, the tractor translational and rotational motions were observed in a global coordinate. According to the de-veloped model, one can obtain the tractor bounce displacement, the pitch angle, and the accel-eration characteristics. Furthermore, the supporting and lateral friction forces can be examined since they predominantly determine the tractor lateral rollover and sideslip which affect tractor safety to a great extent. Therefore, the lateral slope effect on these forces was investigated con-sidering a tractor speed of $0.5 \mathrm{~m} / \mathrm{s}$ and an obstacle height of $0.08 \mathrm{~m}$. Results showed that as the slope angle increases, both the supporting and lateral friction forces put the tractor to a situation closer to danger. In particular, a specific slope angle of $25^{\circ}$ was highlighted as a warning parameter because the onset of rollover as well as tractor sideslip were discovered. It is also found that a tractor is more susceptible to sideslip than rollover along with the slope increasing.
\end{abstract}

Key words: Dynamic Behavior, Lateral Slope Effect, Rollover, Sideslip

\section{INTRODUCTION}

While the agricultural mechanization is globally popularized in recently decades, the safety of agricultural machinery has become a matter of concern. As the majority of farm operations can be achieved by a variety of implements equipped with tractors, it is of necessity to prevent op-erators from injury and death caused by tractor-related accidents. Unfortunately, tractor incident occupies the highest death rate (50\%) considering farm machinery operations according to the report from Ministry of Agriculture, Forestry and Fishers (2013). Insight into the tractor-caused deaths points to the overturning phenomenon which is responsible for $76 \%$ of the total 123 deaths in 2011. Worldwide, the general data indicates that more than half of the tractor fatalities owe to rollover and $75 \%$ to $85 \%$ rollovers are to the side (Abubakar et al., 2010).

To improve tractor safety in the respect of rollover, preference should be on understanding the dynamic behaviors of a tractor encountering obstacles on off-road surfaces, despite of the emergence of the rollover pro-

1 Laboratory of Bioproduction Engineering, Division of Bioproduction Environmental Sciences, Department of Agroenvironmental Sciences, Graduate School of Bioresource and Bioenviron-mental Sciences, Kyushu University

${ }^{2}$ Laboratory of Bioproduction Engineering, Division of Bioproduction Environmental Sciences, Department of Agroenvironmental Sciences, Faculty of Agriculture, Kyushu Universit

* Corresponding author (E-mail: mitsuoka@bpes.kyushu-u.ac.jp) tective structure (ROPS) which provides a passive way to protect operators. While the advantages in rapid design and defect detection can be obtained by using the commercial simulation software for the desired solution such as trajectory or transmission feature of a vehicle (Peters and Iagnemma, 2009; Zhu et al., 2014), it is of significant essence to theoretical study the mechanism of the specific vehicle behavior. To build a tractor mathemati-cal model for predicting its dynamic response, it is appropriate to consider a half sine bump as the road excitation because of its iconicity to reality and continuity for simulation. According to some existing studies, the simplified linear geometric relationships of the arms of forces are commonly adopted in a two-dimensional situation (Homori et al., 2003; Takeda et al., 2010a). While it is acceptable when the tractor rotates slightly, taking into account of nonlinearization would be more applicable to a general rotational case. Furthermore, for practical purpose, con-sidering that the occurrence of rollover as well as tractor sideslip threaten tractor safety significantly, it would be more meaningful to study the behaviors of a tractor on lateral slopes.

Therefore, the objectives of this study are to formulate a mathematical model of a tractor en-countering obstacles on a lateral slope, which is applicable to large tractor rotations, and to pre-dict tractor dynamic responses under the influence of the slope angle.

\section{MATERIALS AND METHODS}

A three-dimensional dynamic model of tractor on 
slope is shown in Fig. 1. In this model, a transverse half sine bump is placed on the designated rigid lateral slope to cause tractor bounce and pitch. To observe the tractor attitude, two coordinates are adopted. One locates at the center of gravity (COG) of the tractor and the other is fixed in space with the $X Y$ plane parallel to the slope surface. The key assumptions used in developing the model are:

- the tractor has a rigid body and travels at a constant speed along the $X$ axis;

- no tractor yaw occurs;

- the concept of effective tire radius by Takeda et al. (2010a) is considered;

- the ground supporting forces are vertical to the lateral slope;

- the tractor body is symmetric to the xz plane.

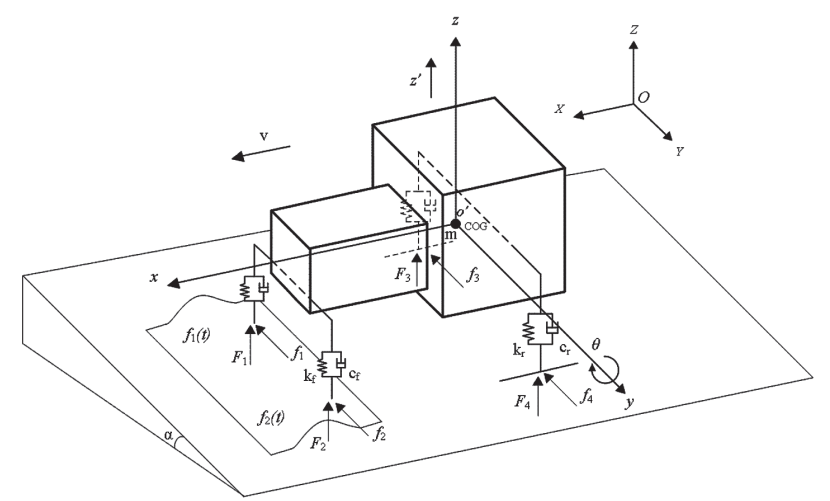

Fig. 1. Three-dimensional mathematical model of tractor traveling over obstacle on lateral slope.

The vertical translational motion with respect to the ground represented in the global coordi-nate $O-X Y Z$ is:

$$
m \ddot{z}=\sum F_{i}-m g \cos \alpha
$$

Although the transverse obstacle is not supposed to excite tractor roll, it is the fact that the ground supporting force of an uphill tire is less than that of the downhill tire. Thus in order to match a general case, tractor roll is taken into consideration for a precise analysis. Subsequently, the initial roll angle due to the slope can be calculated. Note that as the rotational motions are described in the vehicle coordinate, tractor pitch and roll then affect each other by decomposing the ground supporting forces. Therefore, the pitching and rolling behaviors of the tractor are respectively written as:

$$
\begin{aligned}
l_{y} \ddot{\theta} & =\left[l_{1}\left(F_{1}+F_{2}\right)-l_{2}\left(F_{3}+F_{4}\right)\right] \cos \theta \cos \phi \\
& +\left[s_{1}\left(F_{1}+F_{2}\right)+s_{2}\left(F_{3}+F_{4}\right)\right] \sin \theta \cos \phi \\
l_{x} \ddot{\phi} & =\left[w_{1}\left(F_{1}-F_{2}\right)+w_{2}\left(F_{3}-F_{4}\right)\right] \frac{\cos \phi \cos \theta}{2} \\
& +\left[s_{1}\left(F_{1}+F_{2}\right)+s_{2}\left(F_{3}+F_{4}\right)\right] \sin \phi \cos \theta+f H_{G}
\end{aligned}
$$

where $l_{1,2}$ represent the horizontal distances between the COG and the front, rear axles while $w_{1,2}$ are the front, rear tracks; $s_{1,2}$ stand for the initial distances between the COG and the mod-eled front, rear tires; $H_{G}$ is the height of the COG. Furthermore, the lateral friction force $f$ is given by:

$$
f=m g \sin \alpha
$$

To detect the occurrence of tractor sideslip, the decomposed forces $f_{f}$ and $f_{r}$ are assigned in-stead of $f$. By checking the conditions if $f_{f} \geq \mu\left(F_{1}+F_{2}\right)$ and $f_{f} \geq \mu$ $\left(F_{1}+F_{2}\right)$, one can judge the moment and the location of tractor sideslip. From the moment equilibrium at the COG they are identified as:

$$
l_{1} f_{f}-l_{2} f_{r}=0
$$

Unlike the half-track tractor with rubber crawler, which has the nonlinear spring constant $k_{i}$ and viscous damping coefficient $c_{i}$ (Mitsuoka et al., 2008; Inoue et al., 2011), we assumed these parameters to be constant considering the rubber wheels and the constant driving speed, then the ground supporting force $F_{i}$ follows:

$$
F_{i}=-k_{i} d_{i}-c_{i} \dot{d}_{i}
$$

The vertical deformation $d_{i}$ composes of the vertical displacement of the COG, and those caused by tractor pitch, roll, and the obstacle profile, resulting in:

$$
\begin{aligned}
d_{1} & =z+\left[s_{1}(1-\cos \theta)+l_{1} \sin \theta\right] \cos ^{-1} \phi \\
& +\left[s_{1}(1-\cos \phi)+\frac{w_{1}}{2} \sin \phi\right] \cos ^{-1} \theta-\frac{m g l_{2}}{2 k_{1}\left(l_{1}+l_{2}\right)} \\
& -f_{1}(t) \\
d_{2} & =z+\left[s_{1}(1-\cos \theta)+l_{1} \sin \theta\right] \cos ^{-1} \phi \\
& +\left[s_{1}(1-\cos \phi)-\frac{w_{1}}{2} \sin \phi\right] \cos ^{-1} \theta-\frac{m g l_{2}}{2 k_{2}\left(l_{1}+l_{2}\right)} \\
& -f_{2}(t) \\
d_{3} & =z+\left[s_{2}(1-\cos \theta)-l_{2} \sin \theta\right] \cos ^{-1} \phi \\
& +\left[s_{2}(1-\cos \phi)+\frac{w_{2}}{2} \sin \phi\right] \cos ^{-1} \theta-\frac{m g l_{1}}{2 k_{3}\left(l_{1}+l_{2}\right)} \\
& -f_{3}(t) \\
d_{4} & =z+\left[s_{2}(1-\cos \theta)-l_{2} \sin \theta\right] \cos ^{-1} \phi \\
& +\left[s_{2}(1-\cos \phi)-\frac{w_{2}}{2} \sin \phi\right] \cos ^{-1} \theta-\frac{m g l_{1}}{2 k_{4}\left(l_{1}+l_{2}\right)} \\
& -f_{4}(t)
\end{aligned}
$$

It is noted that the method of dividing the obstaclepassing process into four periods is adopted from Yamamoto and Shimada, (1957) and Shimada (1961a, 1961b, 1962), for in-depth analysis. Thus in our case, $f_{1}(t)=f_{2}(t)$ in passage period 1 , while $f_{3}(t)=f_{4}(t)$ in period 3. In pe-riod 2 and 4 , on the other hand, all the obstacle 
profile functions are set to zero.

For global observation, a $3 \times 3$ transformation matrix A is formed basing on the Euler angle. According to the rotation order of roll, pitch and yaw, the global angular velocities can be ob-tained from:

$$
\dot{A^{\mathrm{T}} \mathrm{A}}=\left(\begin{array}{ccc}
0 & -\omega_{z} & \omega_{Y} \\
\omega_{Z} & 0 & -\omega_{X} \\
-\omega_{Y} & \omega_{X} & 0
\end{array}\right)
$$

Further, the corresponding global angles are the integrations of $\omega_{X}, \omega_{Y}$ and, $\omega_{z}$ :

$$
\begin{aligned}
& \theta=\int_{0}^{t} \omega_{Y} d t \\
& \phi=\int_{0}^{t} \omega_{X} d t \\
& \Psi=\int_{0}^{t} \omega_{Z} d t
\end{aligned}
$$

It should also be noted that the yawing phenomenon is not supposed to happen and that trac-tor rolls in a very small range. Therefore the focus of this model is on the responses of tractor bounce and pitch. According to the nonlinear expressions describing the precise geometric rela-tionships in equations (2), (3), and (7) to (10), the model developed is applicable to large tractor bounces and rotations.

\section{RESULTS AND DISCUSSION}

The mathematical model is numerically solved by a computer simulation program whose flow chart is shown in Fig. 2. The key tractor dimensions and physical properties are adopted from the work of Takeda et al. (2010b) while some undeclared parameters are calculated or given by assumption. The program is developed by using Visual Basic Applications within Mi-crosoft Excel. Given the tractor dimensions, driving speed, obstacle profile function and slope parameter, one can obtain the tractor vertical displacement, velocity and acceleration, and likewise the angular values, the supporting and lateral friction forces. It is also possible to check the tire-ground contact condition and tractor sideslip.

Consider a tractor forward speed of $0.5 \mathrm{~m} / \mathrm{s}$, an obstacle height of $0.08 \mathrm{~m}$ and a lateral slope of $5^{\circ}$ as the standard conditions, Fig. 3 shows the simulation results of the tractor bounce dis-placement and the pitch angle. It is obvious that the tendencies of the outputs nearly follow the sine curve but with fluctuations in period 1 and 3 , indicating the responses due to road excita-tion. Because of the bigger size of the rear wheel, the amplitude of vertical displacement in pe-riod 3 appears larger than that in period 1. For the pitch angle, the values turn to minus since the look-up motion is defined as the positive direction.

The acceleration parameters can be calculated in this model as Fig. 4 implies. The division of the overall obstacle-passing process emerges more clearly from the distribution of acceleration values. While the amplitudes practically stay at the same level at all passing stages in

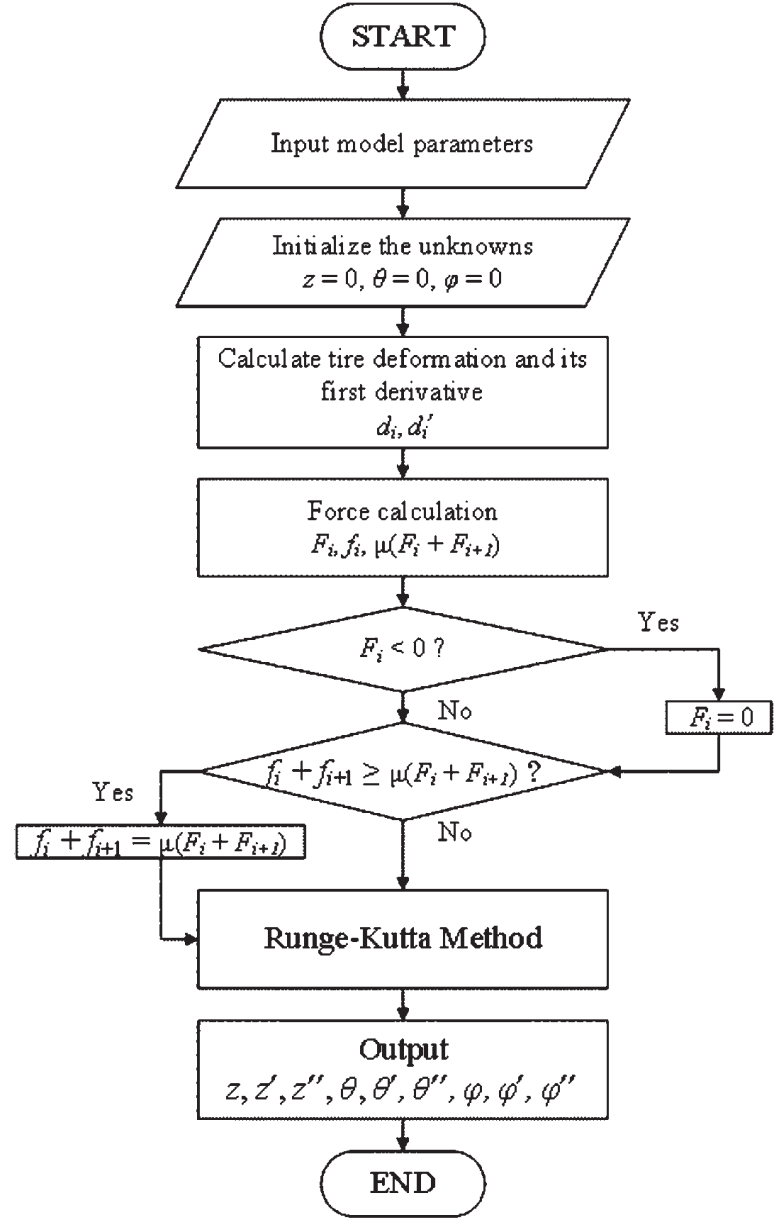

Fig. 2. Program flow chart for numerical analysis of the mathematical model.
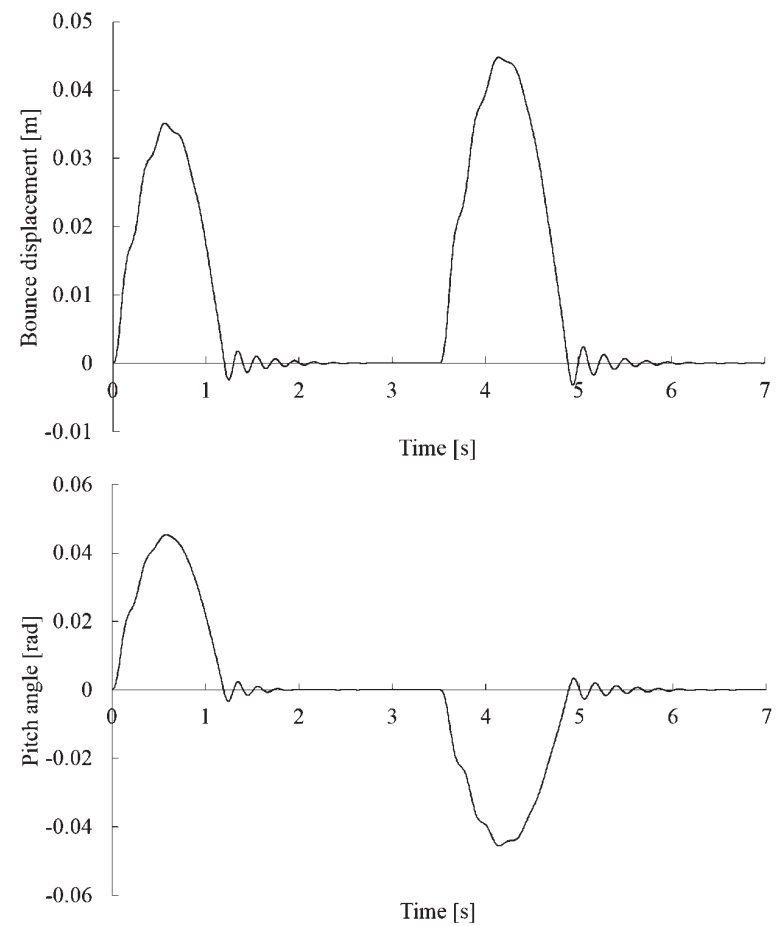

Fig. 3. Tractor bounce displacement and pitch angle of the standard case. 

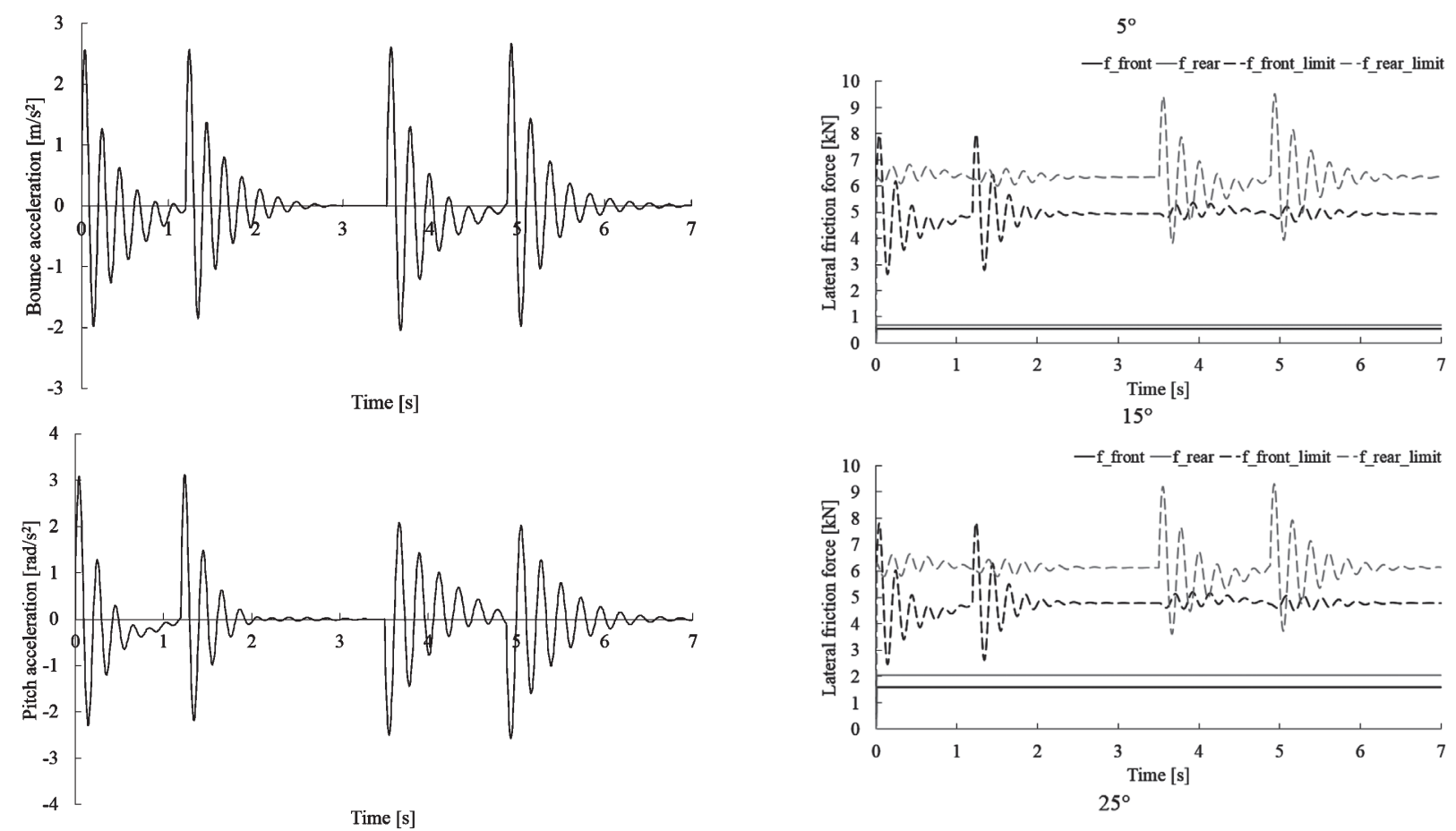

Fig. 4. Tractor bounce and pitch accelerations of the standard case.
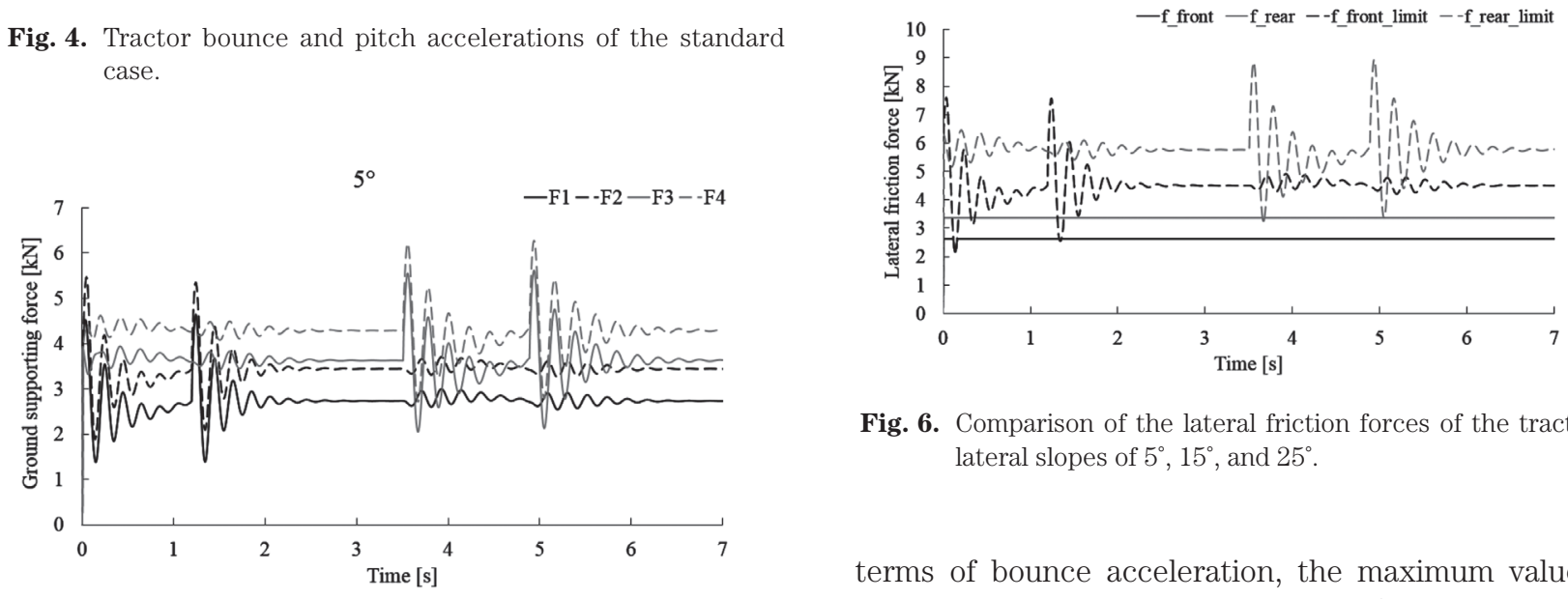

Fig. 6. Comparison of the lateral friction forces of the tractor on lateral slopes of $5^{\circ}, 15^{\circ}$, and $25^{\circ}$.

terms of bounce acceleration, the maximum values of pitch acceleration decrease in period 3 and 4 com-pared to the first two stages.

Noting that the moment the loss of contact of any uphill front or rear tire is traditionally de-fined as the onset of lateral rollover (Guzzomi, 2012) and therefore occurs danger, it is of ne-cessity to check the normal force of each tractor tire. As is shown in Fig. 5, the ground support-ing forces of the uphill tires decrease apparently with the lateral slope climbing, while those of the downhill tires have an adverse tendency. Particularly, the uphill front tire leaves the ground once when the slope angle increases to $25^{\circ}$, and correspondingly the onset of tractor lateral rollover is detected. For the uphill rear tire, the normal force falls under $0.5 \mathrm{kN}$ twice, nearly reaching the onset of rollover. Thus a $25^{\circ}$ lateral slope should be alerted as a risky road condi-tion.

With the lateral slope increasing, as Fig. 6 shows, the ascending possibility of sideslip sig-nificantly encourages tractor instability. While the magnitudes of the both front and rear resul-tant friction forces stay at constant values, the corresponding maximum static friction forces fluctuate due to the variations in the supporting forces caused by uneven ground surface. When a $25^{\circ}$ lateral 
slope is considered, the lateral forces of the both tractor front and rear axles reach their limits for twice, indicating the occurrences of sideslip. In addition, from the results we found that sideslip appeared earlier than the onset of lateral rollover. It should be noted that tractor sideslip is also a considerably risky case in terms of vehicle safety. Hence, the lateral slope of $25^{\circ}$ is again defined as a dangerous case from the respect of sideslip.

\section{CONCLUSIONS}

In this study, a three-dimensional mathematical model describing tractor motions was devel-oped. The new model is applicable to large tractor rotations in a three-dimensional situation. Considering a frequent occurrence of tractor lateral rollover, the sideways slope was introduced to investigate the dynamic variations in the supporting and lateral forces. The interaction between tractor pitch and roll on each other by changing the directions of the supporting forces was considered in this model. Simulations were conducted through the developed program to find the influence of the lateral slope angle on tractor behaviors. A slope angle series of $5^{\circ}, 15^{\circ}$, and $25^{\circ}$ were selected and the constant values of $0.5 \mathrm{~m} / \mathrm{s}$ tractor speed and $0.08 \mathrm{~m}$ obstacle height were designated as the input parameters. From the results, it was found that both the supporting and lateral forces tended to involve the tractor into the onset of rollover as well as sideslip with the lateral slope angle increasing. Specifically, tractor rollover was suspected once while four times for sideslip considering a case of $25^{\circ}$ slope. Thus, for the $25^{\circ}$ slope, a tractor is more susceptible to sideslip rather than rollover. As sideslip is also dangerous and risky to tractor safety, the cor-responding operation on an over $25^{\circ}$ slope is strongly suggested to be avoided.

\section{ACKNOWLEDGEMENTS}

We would like to acknowledge the scholarship support from the China Scholarship Council.

\section{REFERENCES}

Abubakar, M. S., Ahmad, D. and Akande, F. B. 2010 A review of farm tractor overturning acci-dents and safety. Pertanika Journal of Science and Technology, 18(2): 377-385

Ahmadi I. 2011 Dynamics of tractor lateral overturn on slopes under the influence of position disturbances (model development). J. Terramechanics, 48(5): 339-346

Guzzomi, A. L. 2012 A revised kineto-static model for Phase I rollover. Biosystems Engi-neering, 113(1): 65-75

Inoue, E., Mitsuoka, M. and Rabbani, M. 2011 Investigation of nonlinear vibration characteris-tics of agricultural rubber crawler vehicles. AMA, Agricultural Mechanization in Asia, Africa and Latin America, 42(1): 89-93

Mitsuoka, M., Inaba, S., Inoue, E., Fukushima, T., Hara, S., Okayasu, T. and Mori, K. 2008 Prediction and evaluation of vibration characteristics of an agricultural rubber crawler vehicle equipped with movable track rollers. Journal of the Japanese Society of Agricultural Machinery, 70(5): 41-47

Peters, S. C. and Iagnemma, K. 2009 Stability measurement of high-speed vehicles. Vehicle System Dynamics, 47(6): 701720

Report on fatal farming accidents that happened in 2011 (in Japanese, 5 April 2013). Ministry of Agriculture, Forestry and Fisheries of Japan. Available from http://www.maff.go.jp/j/ seisan/sien/sizai/s_kikaika/anzen/pdf/2r23_gaiyou.pdf

Shimada, B. 1961a Transient motion of an automobile passing over an obstacle (part 2). Journal of Society of Automotive Engineers of Japan, 15(5): 204-209, 235

Shimada, B. 1961b Transient motion of an automobile passing over an obstacle (part 3). Joumal of Society of Automotive Engineers of Japan, 15(7): 303-307, 325

Shimada, B. 1962 Transient motion of an automobile passing over an obstacle (part 4, with dumping, coupled: all-inclusive conclusion). Journal of Society of Automotive Engineers of Japan, 16(2): 82-89, 81

Takeda, J., Shimada, M., Kikuchi, Y., Nakano, M., Okada, S., Hiroma T. and Torisu, R. 2010a Dynamic behaviors of farm tractor passing over an obstacle (part 1). Journal of the Japanese Society of Agricultural Machinery, 72(5): 457-463

Takeda, J., Shimada, M., Kikuchi, Y., Nakano, M., Okada, S., Hiroma, T., \& Torisu, R. 2010b Dynamic behaviors of farm tractor passing over an obstacle (part 2). Journal of the Japanese Society of Agricultural Machinery, 72(5): 464-470

Yamamoto, M. and Shimada, B. 1957 Transient motion of an automobile passing over an ob-stacle. Journal of Society of Automotive Engineers of Japan, 11(4): 34-40

Zhu, Z. X., Li, Z., Xie, B. and Mao, E. R. 2014 Virtual prototyping analysis on gear assembly of the power train for a large-scale combine harvester. Applied Mechanics and Materials, 441 635-640 